\title{
Epstein-Barr virus and acute retinal necrosis in a 5-year-old immunocompetent child
}

\author{
Roberto Gallego-Pinazo ${ }^{1,2}$ \\ Miguel Harto' \\ Jose J Garcia-Medina ${ }^{2,3}$ \\ Inmaculada Serra' \\ Enrique España' \\ Maria D Pinazo-Duran ${ }^{2,4}$ \\ 'Ophthalmology Department, \\ University Hospital, La Fe, Valencia, \\ Spain; ${ }^{2}$ Ophthalmology Research Unit \\ "Santiago Grisolia", Valencia, Spain; \\ ${ }^{3}$ Ophthalmology Department, Hospital \\ La inmaculada, Huercal-Overa, Spain; \\ ${ }^{4}$ Ophthalmology Department, Hospital \\ Punta de Europa, Algeciras, Spain
}

Correspondence: Roberto Gallego-Pinazo University Hospital La Fe,

Av/ Campanar 21, 46009 Valencia, Spain

Tel + 34659954094

Email robertogallego@comv.es
Objective: To describe a case of bilateral acute retinal necrosis syndrome (ARNS) in a 5-year-old boy.

Method: A retrospective, interventional case is described in one child attending the pediatric ophthalmology section, complaining of sudden bilateral red eye and haze-impaired vision. A standardized ophthalmologic examination and specific serological probes supported the diagnosis of severe bilateral ARNS in an immunocompetent child.

Results: The reduced visual acuity $(<20 / 400)$, the ocular fundus signs (perivasculitis, thrombosis and retinal edema) and the positive immunoglobulin $\mathrm{M}$ anti-Epstein Barr virus serology, lead us to the ARNS definitive diagnosis. Antiviral therapy (Acyclovir; Zovirax ${ }^{\circledR}$ ), ciclopentolate dilating eye drops, and antiplatelet treatment (acetil salicylic acid; Aspirin ${ }^{\circledR}$ ) were administered until recovering the final visual acuity (20/40).

Conclusions: The ARNS is an ocular disease with poor prognosis, which in turns may display better course when determining the etiopathogenic virus and selecting the appropriate and precocious therapy.

Keywords: retinal necrosis, Epstein-Barr virus, antiviral serology, antiviral therapy

\section{Introduction}

Acute retinal necrosis syndrome (ARNS) was firstly described as Kirisawa-Urayama uveitis in the early seventies (Urayama et al 1971). It is a severe ocular process in which one or both eyes undergoes acute necrosis of the retina, leading to significant visual loss and becoming one major source of legal blindness worldwide (Fischer et al 1982). It has been assumed an immuno-genetic predisposition to the process, without racial predilection but with a higher incidence in males aged 20-55 years (Fischer et al 1982; Tran et al 2004).

Patients may complain of periorbital pain, hazy decreased vision, and red eye. The main clinical signs and symptoms are progressive retinal necrosis with occlusive retinal vasculitis (involving arteries and veins), focal retinitis, optic neuropathy, vitritis, and a high incidence of rhegmatogenous retinal detachment. The latter complicates many cases (up to $2 / 3$ of all ARNS patients). Despite the usual unilateral onset, bilateral affection reaches $80 \%$ of the starting cases in some series (Urayama et al 1971; Fischer et al 1982; Tran et al 2004).

ARNS usually is the result of unknown retinal viral reactivation. Mostly the causal agent is the Herpesviridae familiy, mainly the varicela-zoster virus (Ganatra et al 2000). In adulthood is associated to infection by herpes simplex virus 1 (HSV-1) and the median age is 20 years, but in the case that varicella-zoster virus is involved the median age increases to $45-55$ years. In children the first etiology is the HSV-2 (Tan et al 2001).

Although the ARNS is an ophthalmic process, it has also been described the association to encephalitis (Gain et al 2002; Cardine et al 2004) and dermatitis 
(Nakanishi et al 1999). Because of this, it has to be considered in consultations with other specialists in the context of an infectious process.

\section{Case report}

A 5-year-old boy attended the ophthalmology outpatients care section because of a sudden conjunctival injection with light sensitivity associated to reduced vision $(<20 / 400)$ in both eyes. General signs were mild fever and morbilliform eruptions resembling viral exanthems. The initial presumptive diagnosis was bilateral uveitis. Fundus examination and photographs revealed bilateral ischaemic retina with perivasculitis, retinal edema, and signs of vascular thrombosis.

Based on a history of recurrent oral aphthas, the first diagnosis was incomplete Behçet syndrome, so corticosteroid intravenous therapy was set. However, two days after therapy there was no clinical response and the boy was moved to our pediatric ophthalmology section for further management. Fundus examination revealed intense vitritis and widespread retinal periphlebitis (Figure 1). There was neither macular nor papillary affection (Figure 2 ). However, necrosis patches and focal exudation were observed in the peripheral retina. At this time, the presumption of an infectious etiology was established, so treatment with intravenous acyclovir $\left(\right.$ Zovirax $\left.^{\circledR}\right)$ and acetil salicylic acid (Aspirine ${ }^{\circledR}$ ) was immediately started and a battery of serological tests was performed in parallel. Ciclopentolate dilating eye drops were topically administered every eight hours. Four days later the positive results of the immunoglobulin $\mathrm{M}$ (IgM) anti-Epstein Barr virus (EBV) test were obtained, whereas the rest of serological probes (IgG anti-EBV, CMV, HSV, HIV, Toxoplasma, Chlamydia pneumoniae, and psitacci, Borrellia, Brucella, Mycoplasma, and Treponema) were negatives. At this time, we definitively established the ARNS diagnosis caused by EBV (see Table 1). The patient was confined to intrahospitalary regime and followed-up by means of funduscopic examination every 24 hours. Ten days later IgG seroconversion for EBV was observed. After this, the treatment was managed as described,

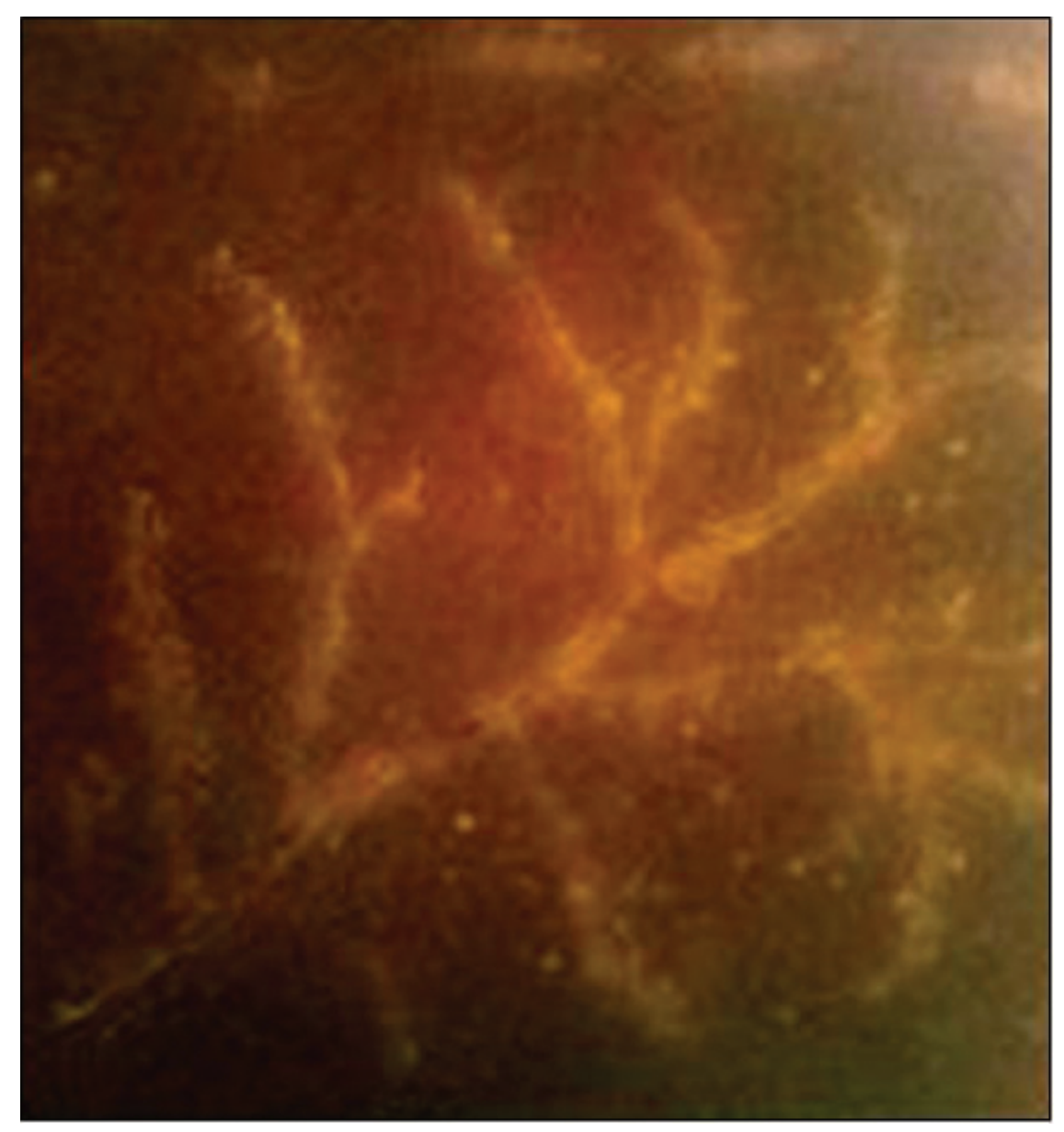

Figure I Retinography at the first examination showing the vitreous body inflammation and retinal periphlebitis. The initial vision was $<20 / 400$ in both eyes. 
the clinical course improved and the patient was discharged from hospital with better vision (20/200 OD and 20/400 OS) (Figure 3). It has to be emphasized that oral acyclovir was recommended to this patient until posterior control appointments. Seven weeks after the admittance, the visual acuity was 20/40 OU and both ocular fundus appeared transparent with scarce pigmented scars in areas where the necrosis first happened, lacking retinal vasculopathy or tears.

\section{Discussion}

Nowadays, ARNS is a not well-known process with a long lasting poor visual prognosis. The presentation in children is quite rare (Ganatra et al 2002; Kolackni et al 2005). In our case the disease bilaterally affected to a 5 year-old immunocompetent boy, displaying the patognomonic signs and symptoms of the Kirisawa-Urayama uveitis, also known as the ARNS (Urayama et al 1971). The etiological diagnosis was reached by the highly suggestive ocular fundus examination, accompanied by the positive results of specific serological probes to the EBV (as shown in Table 1). In spite of the clinical diagnoses, the laboratory probes may be helpful, including: complete blood count, renal and liver functioning, viral titters for HSV 1, HSV 2, and varicella-zoster virus, and other complementary tests) (Knox et al 1998; Zajdenweber and Muccioli 2003). In some cases, image analyses can also help with the clinical managing of the disease, such as fluorescein angiography, ultrasounds, magnetic resonance, etc (Zajdenweber and Muccioli 2003). These latter were not considered essential for managing our study case.

Basic treatment for ARNS mainly includes systemic antiviral therapy (acyclovir), antiinflammatory therapy, antithrombotic therapy and topical cicloplegya. In this context, the role of corticosteroid therapy is uncertain, as shown in an extensive search of the literature, with opinions on the positive antiinflamation effects and the negative immunosupression ones (Blumenkranz et al 1986; Knox et al 1998; Zajdenweber and Muccioli 2003). In addition, some authors have described the use of intravenous or intravitreal

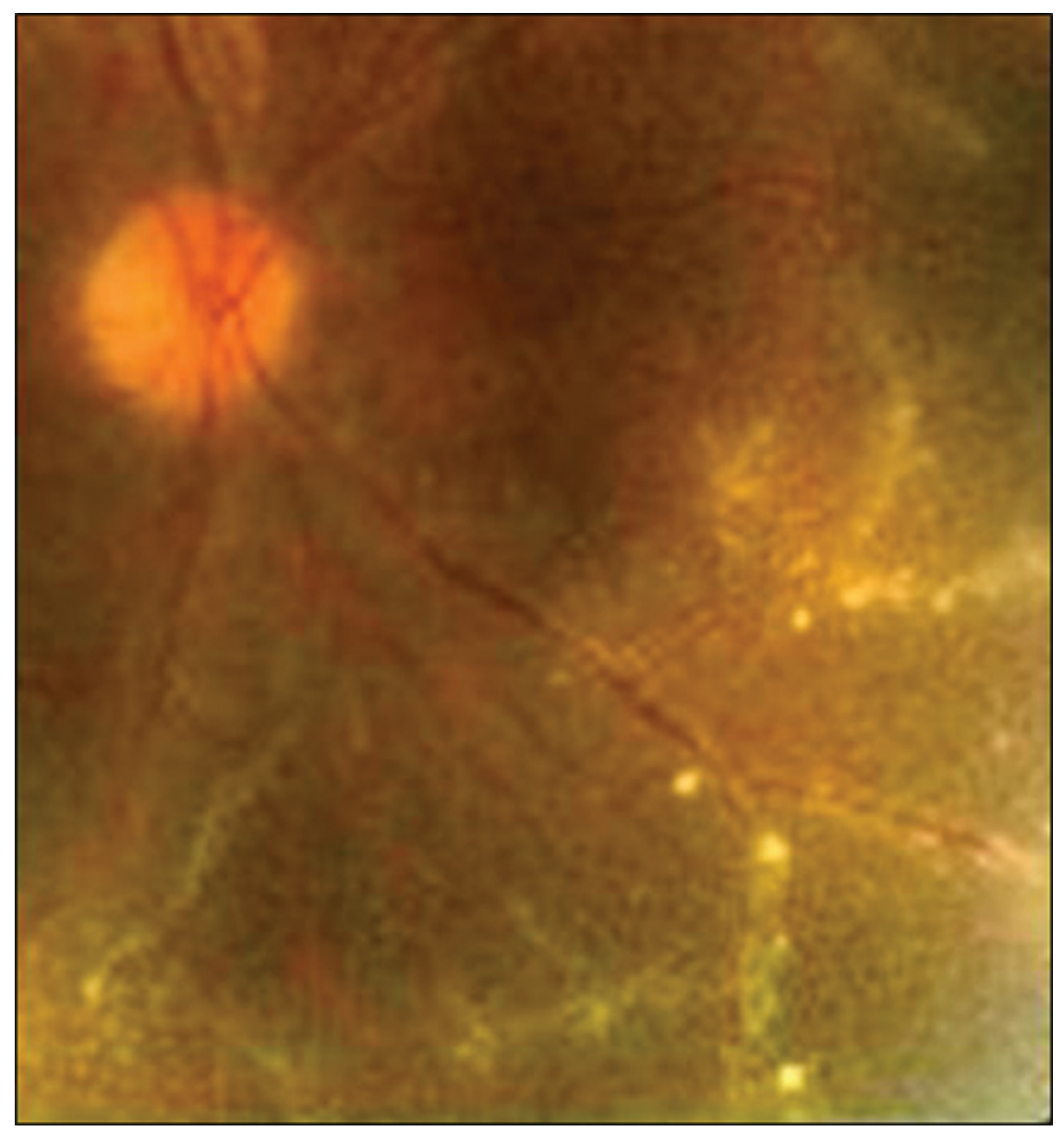

Figure $\mathbf{2}$ In detail, the retinography displays normal appearance of the macula and optic disc. 
Table I Patient characteristics

\begin{tabular}{|c|c|c|c|c|c|}
\hline Age/sex & $\begin{array}{l}\text { Affected } \\
\text { eye }\end{array}$ & $\begin{array}{l}\text { Initial AVOD, } \\
\text { AVOI }\end{array}$ & $\begin{array}{l}\text { Initial } \\
\text { symptoms }\end{array}$ & $\begin{array}{l}\text { Inicial fundus } \\
\text { signs }\end{array}$ & $\begin{array}{l}\text { Diagnostic lab } \\
\text { probes }\end{array}$ \\
\hline 5 years Male & Both & $<20 / 400$ & $\begin{array}{l}\text { Red eyes } \\
\text { Light sensitivity } \\
\text { Impaired vision }\end{array}$ & $\begin{array}{l}\text { Bilateral ischaemic retina } \\
\text { Perivasculitis, } \\
\text { Retinal edema } \\
\text { Vascular thrombosis } \\
\text { Vitritis } \\
\text { No papillary affection }\end{array}$ & $\begin{array}{l}\text { IgM anti-EBV (+) } \\
\text { IgG anti-EBV }(-) \\
\text { CMV (-) } \\
\text { HSV (-) } \\
\text { HIV (-) } \\
\text { Toxoplasma (-) } \\
\text { Chlamydia pneumoniae/ } \\
\text { psitacci (-) } \\
\text { Borrellia (-) } \\
\text { Brucella (-) } \\
\text { Mycoplasma (-) } \\
\text { Treponema(-) }\end{array}$ \\
\hline $\begin{array}{l}\text { Personal } \\
\text { history }\end{array}$ & Fever & $\begin{array}{l}\text { Final AVOD, } \\
\text { AVOI }\end{array}$ & $\begin{array}{l}\text { Final } \\
\text { symptoms }\end{array}$ & $\begin{array}{l}\text { Final fundus } \\
\text { signs }\end{array}$ & Final treatment \\
\hline Oral aphtas & Yes & $20 / 40$ & None & Scarce pigmented scars & $\begin{array}{l}\text { Intravenous acyclovir }\left(\text { Zovirax }^{\circledast}\right) \\
\text { Acetil salicylic acid }\left(\text { Aspirin }^{\circledR}\right) \\
\text { Ciclopentolate eye drops }\end{array}$ \\
\hline
\end{tabular}

Abbreviations: EBV, Epstein-Barr virus; IgG, immunoglobulin G; IgM, immunoglobulin M.

foscarnet (Khurana et al 2005) as well as antiplatelet agents associated with the acyclovir infusion (Carney et al 1986; Han et al 1987; Zajdenweber and Muccioli 2003; Khurana et al 2005). Retinal detachment prophylaxis with laser photocoagulation barricade was also recommended in cases, and surgery for the retinal tears (vtrectomy, endolaser, intraocular tamponade with silicone, octafluoropropane/perfluoropropane) has to be performed when required (Han et al 1987).

For the differential diagnoses it could be necessary to have mainly in mind the following processes: endophthalmitis, CMV retinitis, sarcoidosis, toxoplasmosis, HIV retinitis, and Behçet disease.

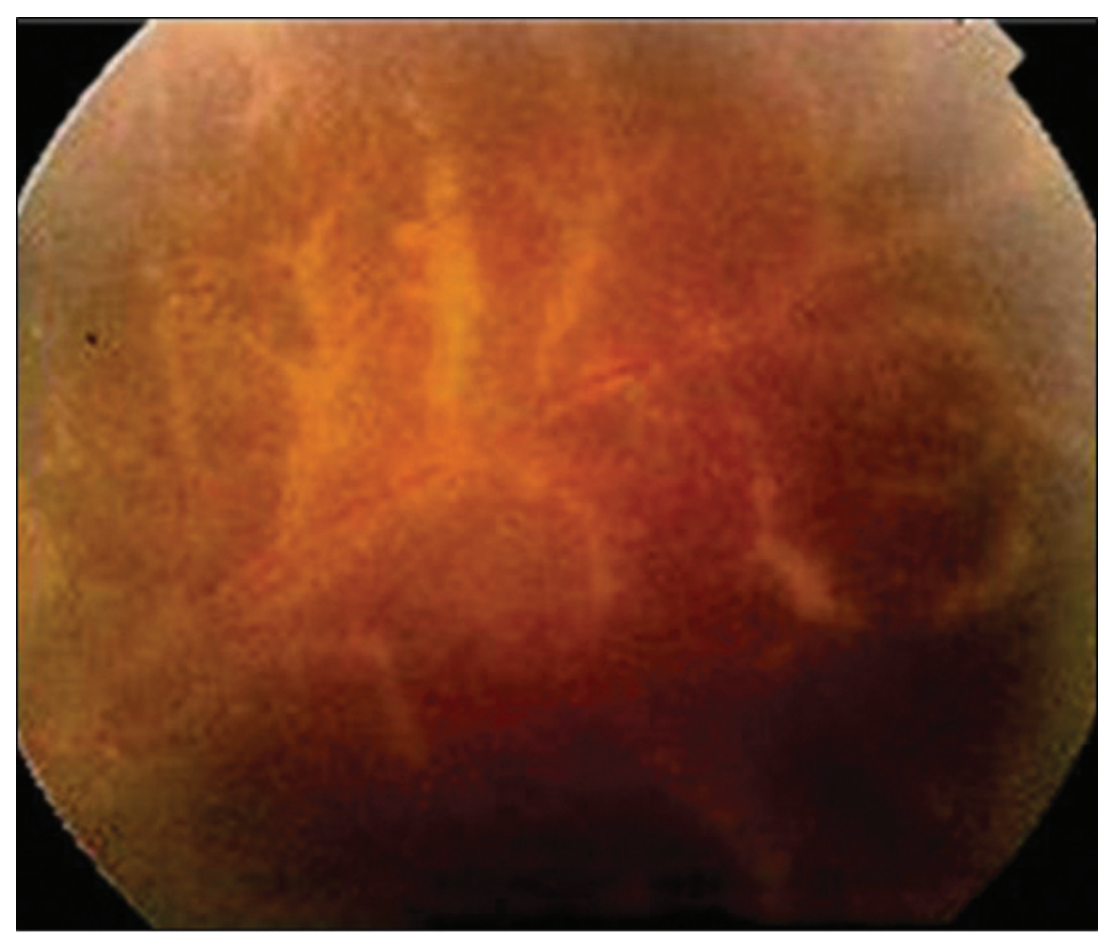

Figure 3 Control retinography in the third week. The final visual acuity was 20/200 OD and 20/400 OS. 
We would like to emphasize that in the case presented herein, the highly favorable response of this boy to the precocious administration of antiviral treatment led us to avoid performing other invasive techniques, such as lumbar puncture (for determining cerebrospinal fluid pleocytosis) and/or PCR on the aqueous humor or vitreous body, as suggested by several authors in other related cases (Han et al 1986; Tan et al 2002; Zajdenweber and Muccioli 2003; Kolacny et al 2005).

Standardized antiviral treatments do not commonly extend beyond two to three weeks. However, the uncertain prognosis of the long-lasting complications (bilateral involvement of the disease, retinal detachment, anterior ischemic optic neuropathy, central retinal artery occlusion, secondary glaucoma, affectation of the optic pathway) strongly recommend that patients with this ophthalmic disease, have to strictly following long-term treatments with oral acyclovir and attending the scheduled control visits. The referred complications go forward up to twenty years after ARNS' first signs and symptoms (Schlingemann et al 1996).

As the ARNS is a sight-threatening process caused by a rapidly progressive retinal infection, prompt treatment is essential for limiting viral reactivation or avoiding neuronal translocation that can lead to further virus spread to other central nervous system structures.

\section{Disclosure}

All authors declare no financial interest in this article.

\section{References}

Blumenkranz MS, Culbertson WW, Clarkson JG, et al. 1986. Treatment of the acute retinal necrosis syndrome with intravenous acyclovir. Ophthalmology, 93:296-300.
Cardine S, Chaze PA, Bourcier F, et al. 2004. Bilateral acute retinal necrosis syndrome associated with meningoencephalitis caused by herpes simplex virus 2. A case report. J Fr Ophtalmol, 27:795-800.

Carney MD, Peyman GA, Goldberg MF, et al. 1986. Acute retinal necrosis. Retina, 6:85-94.

Fisher JP, Lewis ML, Blumenkranz M, et al. 1982. The acute retinal necrosis syndrome. Part 1: Clinical manifestations. Ophthalmology, 89:1309-16.

Gain P, Chiquet C, Thuret G, et al. 2002. Herpes simplex virus type 1 encephalitis associated with acute retinal necrosis syndrome in an immunocompetent patient. Acta Ophthalmol Scand, 80:546-9.

Ganatra JB, Chandler D, Santos C, et al. 2000. Viral causes of the acute retinal necrosis syndrome. Am J Ophthalmol, 129:166-72.

Han DP, Lewis H, Williams GA, et al. 1987. Laser photocoagulation in the acute retinal necrosis syndrome. Arch Ophthalmol, 105:1051-4.

Khurana RN, Charonis A, Samuel MA. 2005. Intravenous foscarnet in the management of acyclovir-resistant herpes simplex virus type 2 in acute retinal necrosis in children. Med Sci Monit, 11:75-8.

Knox CM, Chandler D, Short GA, et al. 1998. Polymerase chain reactionbased assays of vitreous samples for the diagnosis of viral retinitis. Ophthalmology, 105:37-45.

Kolacny D, Stalmans P, Wouters C, et al. 2005. Bilateral acute retinal necrosis in a 12-year-old girl. J AAPOS, 9:599-601.

Nakanishi F, Takahashi H, Ibaraki N, et al. 1999. Acute retinal necrosis with varicella zoster dermatitis in the fellow eyelid. Nippon Ganka Gakkai Zasshi, 103:477-81.

Schlingemann RO, Bruinenberg M, Wertheim-van Dillen P, et al. 1996. Twenty years' delay of fellow eye involvement in herpes simplex virus type 2-associated bilateral acute retinal necrosis syndrome. Am J Ophthalmol, 122:891-2.

Tan JCHD, Byles MR, Stanford PA. 2001. Acute retinal necrosis in children caused by herpes simplex virus. Retina, 21:344-7.

Tran TH, Stanescu D, Caspers-Velu L, et al. 2004. Clinical characteristics of acute HSV-2 retinal necrosis. Am J Ophthalmol, 137:872-9.

Urayama A, Yamada N, Sasaki T. 1971. Unilateral acute uveitis with retinal periarteritis and detachment. Jpn J Clin Ophthalmol, 25:607.

Zajdenweber M, Muccioli C. 2003. Interventions for acute retinal necrosis. Cochrane Database Syst Rev, 3:CD004505. 
